\title{
STAFILINIDOFAUNA LEMNULUI MORT (COLEOPTERA, STAPHYLINIDAE: OMALIINAE, TACHYPORINAE, HABROCERINAE, ALEOCHARINAE, SCAPHIDIINAE, STAPHYLININAE) DIN REPUBLICA MOLDOVA
}

\author{
Mihailov Irina, Bacal Svetlana \\ Institutul de Zoologie, MECC, Chișinău, Republica Moldova \\ irinus1982@yahoo.com, svetabacal@yahoo.com
}

https://doi.org/10.53937/9789975315975.51

\begin{abstract}
The paper presents a complementary contribution to the knowledge of the diversity of Staphylinides in dead wood studied in 6 points in the Republic of Moldova: The Prince's Forest (Padurea Domneasca), Codrii Forest, Plaiul Fagului Forest, Flaminda Forest, Codrii Tigheci, Zabriceni Forest. During the period 2015-2016, 34 species of Staphylinides were identified, of 23 genres in 6 subfamilies: Omaliinae (1 species), Habrocerinae (1), Tachyporinae (8), Aleocharinae (10), Scaphidiinae (2), Staphylinins (12 species). For each species, are presented data on: the place of collection, membership in trophic classification, specification of the geographic element, highlighting common Staphylinides for some investigated stations, etc.
\end{abstract}

Key words: Staphylinidae, dead wood, collection points in Republic of Moldova.

\section{INTRODUCERE}

Din literatură cunoaștem despre importanța lemnului ca material biologic viu în natură și ca materie prelucrătoare în ramurile industriale, însă mai puțin sunt cunoscute aspectele despre lemnul în stare de descompunere. Lemnul, care este denumit "mort", capătă o viață multi-funcțională. Această funcționalitate se evidențiază prin niște procese: de stabilizare a pădurilor; de susținere a productivității în calitate de strat de germinare pentru plante; de asigurare cu hrană și adăpost pentru diferite specii de insecte; de acumulator al carbonului, etc. [1;2].

Printre insectele din ordinul Coleoptera care obișnuiesc să populeze straturile lemnului în faza de descompunere se pot enumera și stafilini- 
dele. Studiile complexului de stafilinide în lemnul descompus din diferite puncte de cercetare sunt desfășurate într-o serie de lucrări științifice [3; 4].

Reeșind din obiectivele specifice de cercetare și din datele prezentate în lucrare, urmărirea stafilinidofaunei în lemnul mort prezintă o continuitate în ideea contribuţiei cunoașterii mai detaliate și îmbunătățirii acestui aspect în punctele de colectare: patru Rezervații Științifice Naturale și 2 Rezervații Peisagistice: 1) Pădurea Domnească - $\left(47^{\circ} 36^{\prime} 35\right.$ „N $27^{\circ}$ 23'37" E) extinsă pe 6032 ha suprafață. Este situată în lunca inundabilă a râului Prut. Vegetația forestieră este formată din stejar, plop, salcie, frasin, ulm și unele specii de conifere; 2$)$ Pădurea Codrii - $\left(47^{\circ} 04^{\prime} \mathrm{N} 28^{\circ}\right.$ $30^{\prime} E$ ) se extinde pe 5177 ha suprafață. Este situată în regiunea centrală a țării. Vegetația forestieră este reprezentată despeciile dominante:stejar, carpen și fag; 3) Pădurea Plaiul Fagului - (47 ${ }^{\circ} 17^{\prime} 28$ „N 28 $\left.8^{\circ} 3^{\prime} 16^{\prime \prime} \mathrm{E}\right)$ are suprafață de 5642 ha, situată în regiunea centrală a țării. În vegetația arboricolă domină stejarul, frasinul și carpenul. Fagul constituie doar 5\%; 4) Pădurea Codrii Tigheci - $\left(46^{\circ} 18^{\prime} \mathrm{N} 28^{\circ} 21^{\prime} \mathrm{E}\right)$ are o suprafață de 2519 ha, este situată pe colinele Tigheciului, în partea de sud a țării. Vegetația forestieră este compusă din gorun în amestec cu stejar pufos; 5) Pădurea Zăbriceni - situată în zona de nord a țării, au fost efectuate colectări în tipul de pădure de stejar cu amestec de frasin și arţar care predomină ca suprafaţă. Aria Zăbriceni se extinde pe o suprafață de 555 ha fiind atribuită la categoria rezervaţiilor peisagistice indicate în art. 442 din „Legea privind Fondul ariilor naturale protejate de stat" publicate în Monitorul Oficial al Republicii Moldova nr.66-68 din 16.07.1998; 6) Rezervația Flămînda reprezintă o extindere cu suprafaţă de 71 ha. Amplasamentul pădurii este ocolul silvic Vulcănești, Flămînda, zona de sud, structurat în sectoare de parcele și subparcele.

\section{MATERIALE ȘI METODE}

În teren: lucrările de acumulare a materialului stafilinic pe parcursul anului 2015 au constat în: • colectări, fixări și etichetări de stafilinide din lemnul mort de pe arbori pe picior, uscaţi și/sau în faza de uscare, de pe arbori căzuţi (doborîtii), din mijlocul trunchiurilor întregiţi și/sau așchiaţi, cioturi și lemn în faze diferite de descompunere,buturugi, ramuri, etc.; 
- secţionarea de elemente lemnoase de vechimi diferite și desprinderi de scoarţă; • prelevări de probe și selectarea acestora; • observaţii directe asupra habitatelor și comportamentului stafilinidelor; •fotografiere etc.

În laborator: •trierea materialului biologic capturat, preparare și clasificare, stocare; $\bullet$ identificarea după caracterele specifice de determinare [5, 6, 8-12]; •clasificarea și nomenclatura taxonomică a stafilinidelor s-a bazat pe sistemul acceptat pe WEB-siturile Fauna Europea [7] și BioLib. cz [6];• analiza datelor: compararea semnalărilor stafilinidelor din punctele cercetate și estimarea numerică a acestora.

Materiale utilizate: săculeţe de polietilenă, tuburi Eppendorf $2 \mathrm{ml}$, ceșcuţe Petri, mănuși de cauciuc, foarfece de tip secator, ace entomologice, lupă, etc.

Metodele aplicate: colectarea manuală, scuturare, greblare, metoda flotaţiei, etc.

\section{REZULTATE ȘI DISCUŢII}

Materialul stafilinic din biotopurile studiate: Rezervațiile naturale Pădurea Domnească, Codrii, Plaiul Fagului, Rezervația peisagistică Pădurea Flămînda, Codrii Tigheci, Pădurea Zăbriceni, enumeră 34 specii, 23 genuri încadrate în 6 subfamilii (tabelul 1).

- Stafilinidofauna din lemnul mort: Rezervația naturală Pădurea Domnească. Stafilinidele selectate din lemnul acestui punct enumeră 4 specii: subfam. Aleocharinae - Aleochara bipustulata (Linnaeus, 1761), Atheta longicornis (Gravenhorst, 1802), Atheta oblita (Erichson, 1839); subfam. Staphylininae - Xantholinus decorus Erichson, 1839.

- Stafilinidofauna din lemnul mort: Rezervația naturală Codrii. Din această arie sunt evidenţiate 7 specii: subfam. Tachyporinae - Sepedophilus littoreus (Linnaeus, 1758), Tachinus corticinus Gravenhorst, 1802, Tachyporus nitidulus (Fabricius, 1781); subfam. Aleocharinae - Gyrophaena joji Wendeler, 1924; subfam. Scaphidiinae - Scaphisoma boleti (Panzer, 1793); subfam. Staphylininae - Quedius limbatus (Heer, 1839), Quedius suturalis Kiesenwetter, 1845.

- Stafilinidofauna din lemnul mort: Rezervația naturală Plaiul Fa- 
gului. Numericul componenţei de specii este mai modest. Sunt identificate stafilinide din subfam. Aleocharinae - Homalota plana (Gyllenhal, 1810); subfam. Staphylininae - Othius punctulatus (Goeze, 1777) și un reprezentant din genul Hypnogyra.

- Stafilinidofauna din lemnul mort: Rezervația peisagistică Flămînda. În acest punct au fost colectate 1 specie din subfam. Aleocharinae - Aleocharabipustulata (Linnaeus, 1760), 1 specie din subfam. Tachyporinae - Tachyporus nitidulus (Fabricius, 1781), și 1 specie din subfam. Staphylininae - Xantholinus tricolor (Fabricius, 1787).

Tabelul 1. Stafilinidofauna lemnului mort din ecosistemul forestier (Pădurea Domnească, Codrii, Plaiul Fagului, Rezenvația Flămînda, Codrii Tigheci, Pădurea Zăbriceni)

\begin{tabular}{|c|c|c|c|}
\hline Subfamilia, Genul, Specia & $\begin{array}{l}\text { Tro- } \\
\text { fica }\end{array}$ & \begin{tabular}{|l|} 
Elementul ge- \\
ografic
\end{tabular} & Staţia cercetată \\
\hline \multicolumn{4}{|l|}{ OMALIINAE Macleay, 1825} \\
\hline \multicolumn{4}{|l|}{ Anthobium Leach, 1819} \\
\hline 1) Anthobium atrocephalum (Gyllenhal, 1827) & Z & Transholarctic & CT \\
\hline \multicolumn{4}{|l|}{ TACHYPORINAE MacLeay, 1825} \\
\hline \multicolumn{4}{|l|}{ Lordithon Thomson, 1859} \\
\hline 2) Lordithon lunulatus Linnaeus, 1760 & S/M & Holarctic & CT \\
\hline \multicolumn{4}{|l|}{ SepedophilusGistel, 1856} \\
\hline 3)Sepedophilus littoreus (Linnaeus, 1758) & Z & Palearctic & $\mathrm{RC}$ \\
\hline 4) Sepedophilus marshami (Stephens, 1832) & Z & Palearctic & PD, CT \\
\hline 5) Sepedophilus testaceus (Fabricius, 1792) & M & Holarctic & $\mathrm{CT}, \mathrm{RC}, \mathrm{PF}$ \\
\hline \multicolumn{4}{|l|}{ Tachinus Gravenhorst, 1802} \\
\hline 6) Tachinus corticinus Gravenhorst, 1802 & Z & Palearctic & $\mathrm{RC}$ \\
\hline \multicolumn{4}{|l|}{ Tachyporus Gravenhorst, 1802} \\
\hline 7) Tachyporus hypnorum(Fabricius, 1775) & Z & Transpalearctic & $\mathrm{CT}, \mathrm{RC}, \mathrm{PZ}$ \\
\hline 8) Tachyporus nitidulus (Fabricius, 1781) & Z & Cosmopolit & $\mathrm{RC}, \mathrm{RF}$ \\
\hline 9) Tachyporus solutus Erichson, 1839 & $z$ & Transpalearctic & $\mathrm{CT}, \mathrm{RC}$ \\
\hline \multicolumn{4}{|l|}{ HABROCERINAE Mulsant et Rey, 1877} \\
\hline \multicolumn{4}{|l|}{ HabrocerusErichson, 1839} \\
\hline $\begin{array}{l}\text { 10) Habrocerus capillaricornis (Gravenhorst, } \\
\text { 1806) }\end{array}$ & $S / Z$ & Palearctic & CT \\
\hline ALEOCHARINAE Fleming, 1821 & & & \\
\hline
\end{tabular}




\begin{tabular}{|c|c|c|c|}
\hline \multicolumn{4}{|l|}{ AleocharaGravenhorst, 1802} \\
\hline 11) Aleochara bipustulata (Linnaeus, 1761) & Z & Holarctic & $\mathrm{PD}, \mathrm{RF}$ \\
\hline \multicolumn{4}{|l|}{ AthetaThomson, 1858} \\
\hline 12) Atheta longicornis (Gravenhorst, 1802) & Z & Euro-Asiatic & PD \\
\hline 13) Atheta oblita (Erichson, 1839) & Z & $\begin{array}{l}\text { Euro-Meditera- } \\
\text { nean }\end{array}$ & PD \\
\hline \multicolumn{4}{|l|}{ Geostiba Thomson, 1858} \\
\hline 14) Geostiba circellaris (Gravenhorst, 1806) & Z & Holarctic & $\mathrm{PD}, \mathrm{CT}$ \\
\hline \multicolumn{4}{|l|}{ Gyrophaena Mannerheim, 1830} \\
\hline 15) Gyrophaena joji Wendeler, 1924 & Z & $\begin{array}{l}\text { Euro-Meditera- } \\
\text { nean }\end{array}$ & $\mathrm{RC}$ \\
\hline \multicolumn{4}{|l|}{ Homalota Mannerheim, 1830} \\
\hline 16) Homalota plana (Gyllenhal, 1810) & Z & Palearctic & PF \\
\hline \multicolumn{4}{|l|}{ Drusilla Leach, 1819} \\
\hline 17) Drusilla canaliculata (Fabricius, 1787) & Z & Palearctic & RC,PF \\
\hline \multicolumn{4}{|l|}{ Ocalea Erichson, 1837} \\
\hline 18) Ocalea badia Erichson, 1837 & Z & Euro-Caucazian & CT \\
\hline \multicolumn{4}{|l|}{ Oxypoda Mannerheim, 1830} \\
\hline 19) Oxypoda opaca (Gravenhorst, 1802) & Z & Palearctic & $\mathrm{CT}, \mathrm{RC}, \mathrm{PF}$ \\
\hline \multicolumn{4}{|l|}{ Phloeopora Erichson, 1837} \\
\hline 20) Phloeopora teres (Gravenhorst, 1802) & Z & Palearctic & $\mathrm{RC}, \mathrm{PF}$ \\
\hline \multicolumn{4}{|l|}{ SCAPHIDIINAE Latreille, 1807} \\
\hline \multicolumn{4}{|l|}{ Scaphisoma Leach, 1815} \\
\hline 21) Scaphisoma boleti (Panzer, 1793) & M & Euro-Caucazian & $\mathrm{RC}$ \\
\hline \multicolumn{4}{|l|}{ Scaphidium Olivier, 1790} \\
\hline 22) Scaphidium quadrimaculatum Olivier, 1790 & M & Est-Palearctic & CT \\
\hline \multicolumn{4}{|l|}{ STAPHYLININAE Latreille, 1802} \\
\hline \multicolumn{4}{|l|}{ Othius Stephens, 1829} \\
\hline 23) Othius punctulatus (Goeze, 1777) & Z & $\begin{array}{l}\text { Euro-Meditera- } \\
\text { nean }\end{array}$ & PF \\
\hline \multicolumn{4}{|l|}{ Gabrius Stephens, 1829} \\
\hline 24) Gabrius femoralis (Hochhuth, 1851) & Z & Euro-Caucazian & CT \\
\hline \multicolumn{4}{|l|}{ Quedius Stephens, 1829} \\
\hline 25) Quedius fulgidus (Fabricius, 1793) & Z & Holarctic & CT \\
\hline 26) Quedius fuliginosus (Gravenhorst, 1802) & Z & Euro-Siberian & $\mathrm{PD}, \mathrm{CT}$ \\
\hline 27) Quedius limbatus (Heer, 1839) & Z & Euro-Caucazian & $\mathrm{RC}$ \\
\hline 28) Quedius nitipennis (Stephens, 1833) & Z & $\begin{array}{l}\text { Euro-Meditera- } \\
\text { nean }\end{array}$ & $R C, P F$ \\
\hline 29) Quedius suturalis Kiesenwetter, 1845 & Z & European & RC \\
\hline
\end{tabular}




\begin{tabular}{|l|l|l|l|l|}
\hline 30) Quedius cruentus (Olivier, 1795) & Z & European & PZ \\
\hline Ontholestes Ganglbauer, 1895 & Z & European & PZ \\
\hline 31) Ontholestes haroldi (Eppelsheim, 1884) & \multicolumn{5}{|l|}{} \\
\hline Xantholinus Dejean, 1821 & S & European & PD \\
\hline 32) Xantholinus decorus Erichson, 1839 & Z & European & PZ, RF \\
\hline 33) Xantholinus tricolor (Fabricius, 1787) & Z & - & PF \\
\hline Hypnogyra Casey, 1906 & 34) Hypnogyra sp.
\end{tabular}

Notă: Trofica: Z - zoofage; M - micetofage; S - saprofage.

Staţia cercetată: PD - PădureaDomnească; RC - RezervaţiaCodrii; PF - PlaiulFagului; RF - RezervațiaFlămînda; CT - CodriiTigheci; PZ - PădureaZăbricei,

- Stafilinidofauna din lemnul mort: Rezervația peisagistică Codrii Tigheci. Sunt identificate 7 stafilinide specifice staţiunii respective. Subfam. Omaliinae - Anthobium atrocephalum (Gyllenhal, 1827), Lordithon lunulatus Linnaeus, 1760; subfam. Habrocerinae - abrocerus capillaricornis (Gravenhorst, 1806); subfam. Aleocharinae Ocalea badia Erichson, 1837; subfam. Scaphidiinae - Scaphidium quadrimaculatum Olivier, 1790; subfam. Staphylininae - Gabrius femoralis (Hochhuth, 1851) și Quedius fulgidus (Fabricius, 1793).

- Stafilinidofauna din lemnul mort: Pădurea Zăbriceni. Din complexul de pădure (stejar cu amestec de frasin și arţar) au fost identificate 4 specii: subfam. Tachyporinae - Sepedophilus testaceus (Fabricius, 1792) și subfam. Staphylininae - Quedius cruentus (Olivier, 1795), Ontholestes haroldi (Eppelsheim, 1884), Xantholinus tricolor (Fabricius, 1787).

În acest context, din analiza tabelului 1 se observă că unele specii sunt comune pentru staţiilecercetate. În PD și CT din eșantioanele selectate au fost extrase speciile Sepedophilus marshami (Stephens, 1832), Geostiba circellaris (Gravenhorst, 1806) și Quedius fuliginosus (Gravenhorst, 1802); în CT+RC+PF: stafilinidele comune sunt Sepedophilus testaceus (Fabricius, 1792), Tachyporus hypnorum (Fabricius, 1775) și Oxypoda opaca (Gravenhorst, 1802); în $\underline{\mathrm{CT}+\mathrm{RC}}$ s-a întîlnit doar o singură 
specie: Tachyporus solutus Erichson, 1839; înRC+PF-Drusilla canaliculata (Fabricius, 1787), Phloeopora teres (Gravenhorst, 1802) și Quedius nitipennis (Stephens, 1833); în $\underline{\mathrm{PZ}+\mathrm{RF}}$ este comună doar specia Xantholinus tricolor (Fabricius, 1787).

În dependenţă de regimul trofic, 28 specii colectate din lemnul mort sunt zoofage iar în grupările: micetofage și saprofage se încadrează câte 3 specii de fiecare. După arealul de răspândire geografică speciile aparţin la 11 elemente zoogeografice: Cosmopolit (1 specie), Est-Palearctic (1), Euro-Asiatic (1), Euro-Caucazian (4), Euro-Mediteranean (4), European (5), Euro-Siberian (1), Holarctic (5), Palearctic (8), Transholarctic (1) și Transpalearctic (2 specii).

Prin studiul stafilinidofaunei lemnului în faza de descompunere și/ sau descompusă putem desprinde niște explicații legate de preferințele ecologice a acestui grup de insecte și de factorul ce influențează atragerea lor spre popularea unui astfel de habitat (substrat). Din urmăririle înregistrate în teren, am observat că: >în majoritatea tipului de lemn mort cercetat, materialul selectat era compus doar din specii de dimensiuni mici și mijlocii (explicația fiind spațiul îngust a fisurilor din interiorul lemnului pentru mișcare); >straturile de lemn mai bogate în vlagă, erau populate de multe alte insecte mici. Acest fenomen, a stimulat apariția stafilinidelor din subfam. Aleocharinae; >efectuând prelevarea probelor în perioade de timp diferită a zilei am observat că orele favorabile pentru extragerea manuală a stafilinidelor din lemn este $10^{00}-13^{00}$. În cazul cînd lemnul a fost secționat și stocat în săculețe pentru transportarea și extragerea în laborator, avantajos în aplicare a fost utilizarea metodei: flotația; >pe suprafața ciupercilor concrescute în fisurile lemnului, s-a observat mobilitatea stafilinidelor din genul Geostibaprin zbor haotic și rapid. Acestea și alte aspecte „zugrăvesc” importanța interrelației staphilinid+lemn în ecosistemul forestier încadrîndu-se în categoria intermediară lanțului trofic și nu de dăunători. 


\section{CONCLUZII}

1. Diversitatea faunistică a stafilinidelor colectate din lemnul mort constituie 31 specii, taxonomic încadrate în 22 genuri, 6 subfamilii: Omaliinae (1 specie), Habrocerinae (1), Tachyporinae (8), Aleocharinae (10), Scaphidiinae (2), Staphylininae (12 specii).

2. Punctele în care s-a studiat diversitatea stafilinică din lemnul în diferite faze de descompunere au inclus 6 stațiuni: Rezervațiile Naturale: Pădurea Domnească, Pădurea Codrii, Plaiul Fagului,Pădurea Flămînda și Rezervațiile Peisagistice: Codrii Tigheci, Pădurea Zăbriceni. Dintre acestea, în Codrii Tigheci, Rezervația naturală Codrii comparativ a rezultat un număr mai mare de specii acumulate în perioada de lucru, (au fost selectate 7 specii din fiecare punct).

3. În plan zoogeografic aceste 34 specii sunt atribuite la 11 elemente zoogeografice: Cosmopolit - 1 specie, Est-Palearctic-1, Euro-Asiatic-1, Euro-Caucazian - 4, Euro-Mediteranean - 4, European - 5, Euro-Siberian - 1, Holarctic - 5, Palearctic - 8, Transholarctic -1 și Transpalearctic -2 specii.

4. Conform spectrului trofic, predomină stafilinidele zoofage în număr de 28urmate de câte 3 specii în fiecare din grupările: micetofage și saprofage.

Studiile au fost realizate în cadrul proiectului instituțional fundamental 15.817.02.12F.

\section{BIBLIOGRAFIE}

1. Lemnul mort dă viaţă pădurii. În:http://www.speo-csm.ro/Lemn-mort. html (15.03.2016).

2. Tomescu R., Târziu D. R., Turcu D-O., Importanţa pentru pădure a lemnului mort. În: Bioflux. ProEnvironment, nr. 4., 2011, p. 104-113.

3. Bacal S., Derunkov A., Rove beetles (Coleoptera, Staphylinidae) from the dead wood in the forestsof Lower Dniester, Republic of Moldova. În: Stu- 
diișicomunicări. ȘtiinţeleNaturii. Craiova, 2009, vol. XXV, p.111-113.

4. Bacal S., Mihailov I.,Calestru L. Contributionto study of staphylinidae (Coleoptera, Staphylinidae) of dead wood in forest ecosystems of Moldova. В: Состояние и перспективы защиты растений.Материалы МежАународной научно-практической конференции, посвященной 45-летию со Аня организации РУП Института защиты растении (Минск-Прилуки, 17-19 мая, 2016). Минск, 2016. с. 322-324.

5. Bouchard P., Bousquet Y., Davies A., Alonso-Zarazaga M., Lawrence J., Lyal Ch., Newton A., Reid Ch., Schmitt M., Ślipiński S.A., Smith A.B.T., Family-group names in Coleoptera (Insecta). In: Zoo Keys.2011.972 p.

6. Biolib.Cz. Biological Library. http://www.biolib.cz/en/stats/id84/(citat 14.01.2008).

7. Fauna Europeae http://www.faunaeur.org/full/results.phpid/11886. (citat 14.01.2008).

8. Lompe V. A.,Kafer Europas.Gattung Sepedophilus Gistel. (Conosoma Motsch.) Coleoptera, Staphylinidae, Tachyporinae. In: http:// www.coleo-net.de/coleo/html/start.htm (08.02.2016).

9. Pietrykowska-TudrujE., Staniec B.,Morphology of the developmental stages of Hypnogyra angularis(Ganglbauer, 1895) (Coleoptera, Staphylinidae, Staphylininae). In: Mitt. Mus. Nat. Kd. Berl. Dtsch. Entomol. Z. 53, 2006, 1, p. 70-85.

10. Telfer M. G. Joy's keys to Tachyporinae. version 2, $11^{\text {th }}$ February, 2012. p. 82-92.

11. Kryzhanovsky O. L., Opredelitel nasekomykh evropeiskoy chasti SSSR, Nauka Publ. Moscow, 1965, vol. 2, 668 p.,

12. Петренко А. А., Шешурак П. М.ВиАовий склаА жуків-стафілініА (Coleoptera, Staphylinidae) Національного Природного Парку "Аеснянсько-Старогутський". В:Фауна і Систематика. Червень, 2013, №1 (6). c. 50-64. 